\begin{tabular}{|c|c|}
\hline I & $\begin{array}{c}\text { International Journal of Current Research } \\
\text { and Academic Review }\end{array}$ \\
\hline 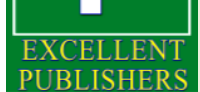 & $\begin{array}{c}\text { ISSN: 2347-3215 (Online) Volume } 7 \text { Number } 3 \text { (March-2019) } \\
\text { Journal homepage: http://www.ijcrar.com }\end{array}$ \\
\hline
\end{tabular}

doi: https://doi.org/10.20546/ijcrar.2019.703.005

\title{
Members' Satisfaction with the Service Performance of Urban Saving and Credit Cooperative Societies: The Case of Gadeb-Hasasa Woreda: Ethiopia
}

\author{
Belay Yadeta and Wondmagegn Urgessa* \\ College of Business and Economics, Department of Management, Wolaita Sodo University, Ethiopia
}

*Corresponding author

\section{Abstract}

This study aims to investigate the members' satisfaction with service performance of urban saving and credit cooperative. SERVPERF model was used to determine members' perceptions of service quality. The present study was conducted at Gadeb-hasasa woreda of Western Arsi zone based on the data that was collected during the year of 2017-2018 to investigate members' satisfaction with the services of urban saving and credit societies the case of Gadeb-hasasa woreda. In this study, multi stage sampling procedure was employed. In the first stage, due to shortage of time and resource, Gadeb-Hasasa woreda was purposively selected for the study. In the second stage, there are two types of saving and credit cooperative societies, urban based and rural saving and credit cooperative societies in the selected woreda. The urban saving and credit cooperative society was selected purposively because of availability of transportation to collect data. In the third stage, there are only two urban saving and credit cooperative societies in this woreda. Therefore, two of them were selected by using census method. In the fourth stage, from the two saving and credit cooperative societies, totally 275 sample size was selected by using simple random sampling method. Both qualitative and quantitative data from the primary and secondary sources were used to undertake this study. Interview schedule was used to collect data for the study. Descriptive statics (Frequency, percentages, mean, standard deviation), inferential statics (reliability test, Pearson correlation, multiple linear regression model) were used to analysis the present study. In this study both descriptive and explanatory study design were used. The main finding of this study was the urban service quality level was medium whereas the members' satisfaction level was high. There was strong relationship between service quality dimensions and members satisfaction. The next major finding of this study was, the assurance, empathy and reliability dimensions of service quality explaining members' satisfaction significantly. Finally, since improvement in assurance, empathy and reliability would lead to increase the members' satisfaction, it is recommended for saving and credit cooperative to invest on them which in turn improve members' satisfaction.
\end{abstract}

\section{Article Info}

Accepted: 04 February 2019

Available Online: 20 March 2019

\section{Keywords}

Members satisfaction, Urban saving and credit, Gadeb-hasasa woreda.

\section{Introduction}

Microfinance industry is now affected by strong competition: "commercial banks have begun to target
MFIs' traditional customers, new MFIs have continued to be created in microfinance industry, and the microfinance customers are becoming more sophisticated concerning the quality of service they require or expect" 
(Daubert, 2002). These factors may negatively affect the MFIs. In fact, the microfinance industry is losing customers because of both the aggressive competition and MFIs' weakness to satisfy their clients (Urguizo, 2006).

This simple description shows why MFIs are concerned about members' satisfaction and retention. It justifies also why they must "pay attention to understand their customers' preferences and priorities" (IFAD, 2007) to survive in a competitive environment. The microfinance industry is quite slowly in becoming more "market oriented" and it seems that customer satisfaction is one of the important tools to run a business and to achieve the mission statement (on sustainability and outreach) in this sector.

Customer satisfaction is an evaluative process, it is defined as "a judgment that a product of service feature, or the product or service itself, provided (or is providing) a pleasurable level of consumption related fulfillment, including levels of under or over fulfillment" (Oliver 1997, 13) cited by (Swaid, 2007). Customer satisfaction is "captured as positive feeling (satisfaction), indifference or negative feelings (dissatisfaction)" (Bhattacherjee, 2001) cited by (Swaid, 2007). It is a short-term attitude that can readily change given a constellation of circumstances. Therefore, satisfaction is not a static idea and it changes as soon as a client finds a better deal that meets his expectations. In this perspective, firms must focus on customer satisfaction, studying and determining as soon as possible the customer satisfaction level, to adjust the product to customer needs. Indeed, customer satisfaction has great significance for the future of an institution and it is seen as a basis for securing market position and achieving other objectives of the institution (Koraus, 2002). Saving and credit cooperative societies must consider its specific situation and its members' needs and expectations. This will in turn improve members' retention, improve products and identify those that are most profitable members. One of the ongoing challenges faces Saving and credit cooperative societies in Ethiopia is optimizing members satisfaction and developing clients relationship management, thus in order to raise clients satisfaction levels ,Saving and credit cooperative societies must invest in selecting the correct people who not only have the functional, technical competence but also have the right attitude (Adjei and Arun, 2009).

Saving and credit cooperative societies like other microfinance institutions are losing customers because of both aggressive competition and microfinance institutions weaknesses to satisfy their clients (Urquizo, 2006). This simple description shows why microfinance institutions are concerned about customer satisfaction and retention. It also justifies why they must "pay attention to understand their customer's preferences and priorities. To survive in a competitive environment, the microfinance industry has been slow in becoming more "market oriented" and it seems that customer satisfaction is one of the most important tools to run a business and to achieve the mission statement (on sustainability and outreach) in this sector (IFAD, 2007).

In this perspective, firms must focus on customers satisfaction, studying and determining as soon as possible the customer satisfaction level, to adjust the product to customer needs. Indeed, customer satisfaction has great significance for the future of an institution and it is seen as a basis for securing market position and achieving other objectives of the institutions (Koraus, 2002); cited by (Kanyurhi, 2013).

\section{The following hypothesis were tested in this study}

$\mathbf{H}_{1}$ : There is positive and significant relationship between assurance and customer satisfaction (Bersisa, 2015).

$\mathbf{H}_{2}$ : There is positive and significant relationship between empathy and customer satisfaction (Samuel, 2016).

$\mathbf{H}_{3}$ : There is positive and significant relationship between reliability and customer satisfaction (Samuel, 2016).

$\mathbf{H}_{4}$ : There is positive and significant relationship between responsiveness and customer satisfaction (Bersisa, 2015).

$\mathbf{H}_{5}$ : There is positive and significant relationship between tangible and customer satisfaction (Bersisa, 2015).

$\mathbf{H}_{6}$ : the all service quality dimensions assurance, empathy, reliability, responsiveness, and tangible explain the customer satisfaction significantly (Asfaw, 2015).

\section{Theoretical review}

\section{Evolution of customer satisfaction measurement}

There are many techniques and methods for measuring customer satisfaction. In this study the researcher wouldn't review all existing methods. Therefore, regarding the models of measuring service quality, for 
the purpose of this study, limited to representative methods like SERVQUAL, SERVPERF and some adapted methods resulting to SERVQUAL model was reviewed.

\section{Service quality model}

The SERVQUAL model is considered as the pioneer model in customer satisfaction measurement. Developed by Parasuraman et al., (1985), the model has been recognized as the most representative tool in approaching customer satisfaction issues. The central idea is that service quality is "a function of the difference scores or gaps between expectations and perceptions $(\mathrm{P}-\mathrm{E})$ ". "SERVQUAL contains 22 pairs Likert scale statements structured around five service quality dimensions in order to measure service quality (Cronin and Taylor 1992):Reliability, Responsiveness, Assurance , Empathy , Tangibles )" (Bloemer, Ruyter et al., 1999).

In this perspective, customer satisfaction is analyzed as multidimensional concept resulting from a comparative approach between customer's expectations and perceived quality delivered by the firm (Parasuraman et al., 1985). Thus, "a positive gap score implies that expectation have been met or exceeded and a negative score implies that expectations are not being met" (Parasuraman et al., 1988) cited by (Safakli, nd, Barnes, 2005, Parasuraman et al., 1985). Now, SERVQUAL model is analysed and modified by some authors seeking to adapt it or to correct some mistakes it may be perceived to contain. Rethinking Service quality has given birth to multiple others models among them SERVPERF which was analyseg below.

\section{The SERVPERF model}

This model had been developed by Cronin and Taylor 1992 from SERVQUAL model basis. The fundamental criticism launched to SERVQUAL model by Cronin, Taylor and other authors like Teas concerns the gap scores (P-E). In fact, those authors estimated that "there are serious problems in conceptualizing service quality as a difference score" (Cronin and Taylor 1992, 26). Thus, SERVPERF model suggests "that customer satisfaction with service is based only on "performance" rather than a gap between performance and expectations, with the performance-only scale termed SERVPERF" (Cronin and Taylor 1992, 1994).

However, SERVPERF model is composed of the same 22 perception items included in SERVQUAL. "It excludes any consideration of expectation, which makes SERVPERF a more efficient measure in comparison to SERVQUAL. Empirical studies have confirmed a relative superiority of SERVPERF to SERVQUAL models. Thus, PZB 1994 argued that "SERVPERF has greater construct validity and that SERVPERF measures also exhibit convergent and discriminate validity" (Cronin and Taylor, 1992).

\section{Adapted models from SERVQUAL mode}

Today, SERVQUAL model is adapted from marketing to finance sector. The principal SERVQUAL model has been changed in function of authors' research and interest. Many modifications are have been done by diminishing or adding some items or dimensions to the original model. Thus, for example, the PAKSERV model is using "SERVQUAL dimensions of tangibility, reliability and assurance but replaced the responsiveness and empathy dimensions with three new dimensions: Sincerity (consumer's evaluation of the genuineness of the service personnel), Formality (consumer's evaluation of social distance, form of address and ritual) and Personalization (consumer's evaluation of individualize and individualized attention)" (Saunders, nd).

The BANKSERV model adopts a 'perceptionexpectation' approach to the measurement of service quality. "The model contains 17 items regrouped in four main factors: staff conduct, credibility, communication, access to Teller Services" (Pont and McQuilken, 2002) for assessing customer satisfaction in bank sector in Australia. The CARTER model was been developed to adapt SERVQUAL to Muslim culture enabling it to measure customer satisfaction in Islamic banks.

The model makes assumption that the cultural and religious influences were significantly rated and placed in the front by Islamic banks customers. CARTER model includes 6 dimensions with 34 items. It includes in addition to the compliance with Islamic law and principles all SERVQUAL five dimensions" (Othman et al., 2001).

\section{Empirical review}

\section{Customer satisfaction}

Satisfaction is defined as "entire customer attitude react toward service provider" (Levesque and McDougall, 1996). Gerpott, Rams and Schindler (2001) indicated customer satisfaction level was measure based on 
previous experience of customer with service provider. Customer satisfaction level increases as service provider success in accomplishing their expectation. Fornell et al., study (as cited in Hellier et al., 2003) stated service quality is major element of customer satisfaction. Emotive satisfaction valuation was affected by service quality appraisal of service based company (Bagozzi, 1992).

Customer perception of service quality is the major causes of customer satisfaction (Cronin et al., 2000). There are a few measurement suggest by Heskett et al., (as cited in Levesque and McDougall, 1996) which often used by researchers on their research and normally included entire service quality, reach expectation of service demander and customer satisfaction. A high standard service quality will lead to long term profitability since it influenced the repurchase intention of customers (Leverin and Liljander, 2006). Glaveli et al., (2006) indicated level of satisfaction regarding to the service quality increases when service provider could deliver on time service.

For researches that studies on UK financial service, Maddern et al., (2007) had conducted a study to identify the main element which lead to customer satisfaction. The study shown service quality is the major influence of customer satisfaction which can be obtained from the result of service profit chain. Apart from this, technical service quality (TSQ) is important as the driver of customer satisfaction levels which is in consistent with the finding of Newman (2001). Maddern et al., (2007) explained technical service quality responsible in recover the poor operational behaviour since excellent performance of front -office employees could not fully offset poor operational process.

\section{Materials and Methods}

\section{Research design}

Both descriptive and explanatory study design were used to conduct this research. Application of descriptive study design was chosen as the researcher was interested in describing the existing service quality dimensions that lead to customer satisfaction. This study also uses explanatory study design, to explain and understand the relationship between variables. The study is also crosssectional as relevant data was collected at one point in time.
Population, Sample and sampling procedures

In this study, multi-stage sampling techniques were employed. In the first stage, Gadeb-Hasasa woreda was selected by using purposive sampling techniques for the study due to shortage of time and resources.

In the second stage, there are two types of SACCO's namely urban (Urban SACCO'S) and rural SACCO's in the selected woreda. The urban SACCOs was selected by using purposive sampling technique due to availability of data for the research and transportation services to collect data in this woreda. In the third stage, there are only two urban SACCO's (Ogey barnota and Yekatiti 25 ) in this woreda. Therefore, two of them were selected by using census method for the study.

From the total numbers of members found in Yekatit 25 saving and credit cooperative society and Ogey barnot saving and credit cooperative society, members stayed one year and above in both SACCO'S would be the population of the study. The sample size of the study is determined by using formula developed by Yamane (1967: 886) in the following way.

$$
\mathrm{n}=\frac{N}{1+N(\mathrm{e})^{2}}
$$

Where $\mathrm{n}$ is the sample size, $\mathrm{N}$ is the population size, and $\mathrm{e}$ is the level of precision.

A 95\% confidence level and $\mathrm{P}=.5$ are assumed for equation. Accordingly, the total numbers of members stayed in both Yekatit 25 saving and credit cooperative society and Ogey barnot saving and credit cooperative society 243 and 642 respectively. The sum of both cooperative which is 885 is the population of the study. Therefore, the sample size of the study is calculated in the following way by using Taro Yamane.

$$
\begin{aligned}
& \mathbf{n}=\frac{885}{1+885(0.05)^{2}} \\
& \mathbf{n}=\mathbf{2 7 5}
\end{aligned}
$$

The probability proportionate technique was used to determine the sample size taken from the two SACCO's by using the following formula.

$$
\mathbf{n} 1=\frac{\mathbf{n N} 1}{\mathrm{~N}}
$$


- Where $\mathrm{n}=$ total number of samples

- $\mathbf{N}=$ total number of customers from sample SACCO's

- $\quad \mathbf{N 1}=$ total number of customers at each SACCO's

- $\quad \mathbf{n 1}=$ sample size from each SACCO's

Therefore, 199 members from Ogey barnot and 243 from Yekatit25 were taken for the study. Totally 275 sample size was taken from both SACCO's. In the fourth stage, the probability sampling method was used to choose respondents from the selected SACCO's to collect information necessary for the study (Table 1).

\section{Scale and measurement}

In this study as overall SERVPERF scale was employed to measure urban saving and credit services .In addition, in order to measure service quality level and the level of members' satisfaction, mean score value of five likert scale categorization used by Ahmed (2013) was employed. According to this mean score categorization on the five likert scale measurement, from the below table 2 , it observed that the value obtained from five likert scale categorized in to 3 groups. As per of this standard requirements, interpretation of mean score throughout this research put as the following. As far as the service quality level, service quality dimensions and members satisfaction mean interpretation were concerned, if the value is 3.5 or higher, it would be considered as "High Level". If the value is 2.5 to 3.4, then it would be interpreted as "Medium Level". If the value is 2.4 or lower, then it would be interpreted as "Low Level". This interpretation is strictly based on the domain and the requirements of the survey.

In order to test the hypothesized relationships, the main constructs/attributes measured in this study include the following: as independent variables, service quality dimensions are: tangibility, reliability, responsiveness, assurance, and empathy and as dependent, variable, customer satisfaction. All the instruments are adapted from existing literature. Based on the literature the study used the following cues as measures of the variables in the study.

\section{Results and Discussions}

\section{Reliability analysis}

Table 3 below showed that overall reliability analysis of Cronbach's alpha coefficients for the study and each service quality dimensions was greater than $\mathbf{( 0 . 8 9 7 )}$ and which is higher than benchmark of $\mathbf{0 . 7 0}$ of Cronbach's Alpha. These high Cronbach's alpha coefficients indicated that each construct had high internal consistency among the items measuring the constructs.

\section{Descriptive statistics of SERVQUAL dimensions of urban SACCO's}

Under this topic ,the mean score, standard deviation and frequency of tangible, reliability ,responsiveness , assurance a empathy overall service quality and overall members' satisfaction were discussed

\section{Tangibility}

The table 4 showed that the mean score and standard deviation of components of tangibility and tangibility of sample respondents. Based on the table 4, the mean score and standard deviation of tangibility was (2.9427) on the 5likert scale measurement and (0.87510) standard deviation. Since mean score of tangibility on the 5 likert scale measurement was between (2.5) and (3.4). Therefore the mean score of tangibility from the table was medium. In addition, on the focus group discussion held with selected respondents also members didn't give high emphasis about the physical appearance of SACCO'S equipment support this finding, but they give emphasis on the way the employees treat them.

The figure 1 below showed that $32.35 \%$ of sample respondents' satisfaction to the tangible was with in high category where as $40.81 \%$ of sample respondents' satisfaction was with in medium and $26.84 \%$ of respondents' satisfaction was within low category. From this figure it could be concluded that about $73.16 \%$ of respondents were satisfied with tangible dimensions of service quality.

\section{Reliability}

The table 5 below indicated that the mean score of the reliability on the five likert scale measurement was (3.3713). Therefore, since the mean score value of the reliability lies in between 2.5 to 3.4 , it was categorized under medium. In addition, the standard deviation of the reliability was $(0.84534)$.

The figure 2 indicated that $46.32 \%$ of sample respondents' satisfaction to the reliability was with in high classification where as $39.34 \%$ of sample respondents' satisfaction was with in medium and 
$14.34 \%$ of respondents' satisfaction was with in low group. From this figure it could be concluded that about $85.66 \%$ of respondents were satisfied with reliability dimensions of service quality.

\section{Responsiveness}

The table 6 below depicted that the mean score of the responsiveness responded by the sample respondents on the five likert scale was (3.2748). This mean value lies in between (2.5) and (3.4) which is category of medium. Therefore, the mean score of responsiveness was medium. Lastly, the standard deviation of sample respondent's perception on the responsiveness dimension on the fivelikert scale was (0.99193).

The figure 3 below pointed out that $51.84 \%$ of sample respondents' satisfaction to the responsiveness was with in high category where as $28.31 \%$ of sample respondents' satisfaction was with in medium and 19.85 $\%$ of respondents' satisfaction was with in low classification. From this figure it could be concluded that about $80.15 \%$ of respondents were satisfied with responsiveness dimensions of service quality.

\section{Assurance}

From the table 7, it was seen that the sample respondent's perception to the assurance dimension measured by using five likert scale mean score was (3.4366). Since, the mean score of respondent's perception on assurance was lies in between (2.5) and (3.4), the mean score of the sample respondent's on assurance was medium. Additionally, the standard deviation of sample respondent's from the mean was (.95318).

The figure 4 below revealed that $54.41 \%$ of sample respondents' satisfaction to the assurance was with in high group where as $31.25 \%$ of sample respondents' satisfaction was with in medium and $14.34 \%$ of respondents' satisfaction was with in low category. From this figure it could be concluded that about $85.66 \%$ of respondents were satisfied with assurance dimensions of service quality.

\section{Empathy}

The table 8 reveals that the mean score of respondents' perception towards empathy dimension that was measured on the five likert scale was (3.2426). Since the mean score calculated from the five likert scale was categorized as low $(<=\mathbf{2 . 4})$ medium (2.5-3.4) and high $(>=3.5)$, the mean score of empathy was in between (2.53.4).Therefore, the mean score for empathy was medium.

The below figure 5 portrayed that $42.65 \%$ of sample respondents' satisfaction to the empathy was with in high category, where as $39.34 \%$ respondents' satisfaction to urban SACCO's was with in medium category and respondents whose satisfaction with in low category was $18.01 \%$. From the below figure, it could be concluded that majority urban SACCO's (81.99\%) of members were satisfied with empathy dimensions of service quality.

\section{The mean of service quality dimensions and overall service quality}

The table 9 below showed that the mean score of service quality dimensions tangibility, reliability, responsiveness, assurance, empathy and overall service quality of sample respondents' as measured by using five likert scale were (2.9427), (3.3713), (3.2748), (3.4366), (3.2426) and (3.2584) respectively. Thus, based on the mean score categorization of data collected through five likert scale measurement, the tangibility (low), reliability (medium), responsiveness (medium), assurance (high), empathy (medium) and overall service quality(medium).

In addition, table 9 portrayed that the standard deviation of each service quality dimensions and overall service quality. The standard deviation of tangible, reliability, responsiveness, assurance, empathy and overall service quality were (0.87510), (0.84534), (0.99193), (0.95318), (0.88310) and (0.76990) respectively. Finally, what the table 9 below depicted was the contribution of each service quality dimensions to the overall service quality. In this regard, based on their contribution to the overall service quality, $1^{\text {st }}$ rank (3.4366), $2^{\text {nd }}$ rank (3.3713), $3^{\text {rd }}$ rank (3.2748), $4^{\text {th }}$ rank (3.2748) and $5^{\text {th }}$ rank (2.9427) for assurance, reliability, responsiveness, empathy and tangible respectively.

\section{Assessing the level of SACCO's service quality}

An average scoring method was employed to reach at the level of customer satisfaction which is given out of $100 \%$. The next histogram encapsulated the average customer satisfaction score for the data set. The figure 5 below showed that the mean of overall service quality was 3.26 with standard deviation of 0.77 . The mean score of overall service quality was medium which indicated that majority of sample respondents were 
satisfied by the overall service quality provided by the urban saving and credit cooperative societies.

\section{The mean score of overall members' satisfaction to the SACCO's services}

From the table 10 below, it was observed that the mean score of overall members' satisfaction with saving and credit cooperative service as measured using five likert scale was (3.4969). From the table 10 below, it is possible to say that sample respondents' overall satisfaction to saving and credit cooperative was high by using five likert scale measurement mean score value categorization. In addition, the standard deviation of overall members' satisfaction was (0.87602).

The below figure 6 portrayed that $58.09 \%$ of sample respondents' satisfaction to the overall urban SACCO's services was with in high category and $30.51 \%$ of respondents were those whose satisfaction level was with in medium and $11.40 \%$ of sample respondents were those whose satisfaction level was with in low category. From this figure, it could be concluded that $88.6 \%$ respondents were satisfied with urban saving and credit cooperatives.

\section{Assessing the Level of members' Satisfaction}

There were six items that inquired about customer satisfaction directly. An average scoring method was employed to arrive at the level of customer satisfaction which is given out of $100 \%$. The following histogram summarizes the average customer satisfaction score for the data set. The figure 7 below depicted that the mean satisfaction was 3.5 with standard deviation of 0.876 . The mean satisfaction score was high which indicated that the majority of sample respondents were satisfied with the service provided by the urban saving and credit cooperative societies.

\section{Inferential analysis}

Inferential analysis employed in this study were reliability test, Pearson correlation and multiple linear regression In addition varies techniques were employed to test assumption of multiple linear regression model.

\section{Correlation analysis}

The researcher investigated the questions of whether there was positive and significant relationship between service quality dimensions (tangible, reliability, responsiveness, assurance, and empathy) and overall members' satisfaction. From the table 11 below, Spearman correlation coefficient indicated that there was a strong, positive and significant relationship between service quality dimensions tangible, reliability, responsiveness, assurance, empathy and overall members' satisfaction ( $\mathrm{r}=0.548$, Sig.2 tailed $=0.000)$, $(\mathrm{r}=0.700, \quad$ Sig.2-tailed $=0.000), \quad(\mathrm{r}=.629, \quad$ Sig.2tailed=0.000), $(\mathrm{r}=0.690$, Sig.2-tailed $=0.000), \quad(\mathrm{r}=0.744$, Sig.2 tailed $=0.000$ ) respectively. The findings of this research was similar with (Bersisa, 2015) and (Asfaw, 2015). Thus, it was possible to conclude that with the confidence of more than $95 \%$, there was positive, strong and significant relationship between service quality dimensions tangible, reliability, responsiveness, assurance, empathy and overall members' satisfaction. Besides, upon the focus group discussion, they would support the idea that the existence of strong relationship between service qualities dimensions and members' satisfaction.

\section{Multiple linear regression analysis}

As a predictive analysis, multiple linear regressions is used to describe data and to explain the relationship between one dependent variable and two or more independent variables.

\section{The Assumptions of multiple linear regression model}

Assumption 1: The relationship between the independent variables and the dependent variable is linear

The first assumption of Multiple Regression is that the relationship between the independent variables and the dependent variable can be characterized by a straight line. A simple way to check this is by producing scatter plots of the relationship between each of the independent variables and the dependent variable.

Assumption 2: There is no multi-Co linearity in the data

This is essentially the assumption that the predictors are not too highly correlated with one another.

Assumption 3: The values of the residuals are independent

This is basically the same as saying that it is needed that the observations (or individual data points) to be independent from one another (or uncorrelated). 
Assumption 4: The variance of the residuals is constant

This is called homoscedasticity, and is the assumption that the variation in the residuals (or amount of error in the model) is similar at each point across the model. In other words, the spread of the residuals should be fairly constant at each point of the predictor variables (or across the linear model).

Assumption \#5: The values of the residuals are normally distributed

This assumption can be tested by looking at the distribution of residuals (Fig. 10).

Assumption \#6: There are no influential cases biasing the model.

Significant outliers and influential data points can place undue influence on the model, making it less representative of the data as a whole.

Assumption \#1: The relationship between the independent variables and the dependent variables are linear

Looking at the figures 8 , it can be seen that the relationship between the independent variables and the dependent variable could be modelled by a straight line. The below figures were suggesting that the relationship between these independent variables and dependent are linear.

Assumption\#2: There is no multi-Collinearity in the data

The first assumption the researcher can test is that the predictors are not too highly correlated. Researcher can use VIF and Tolerance statistics to assess this assumption. For the assumption to be met the researcher want VIF scores to be well below 10, and tolerance scores to be above 0.2 ; which is the case in this research.

Assumption \#3: The values of the residuals are independent

To check the next assumption the researcher need to look at the Model Summarybox. Here, the researcher can use the Durbin-Watson statistic to test the assumption that the residuals are independent (or uncorrelated). This statistic can vary from 0 to 4 . For assumption \#3 to be met, researcher want this value to be close to 2 . Values below 1 and above 3 are cause for concern and may render the analysis invalid. In this case, the value is 1.825 , so, this assumption has been met.

Assumption \#4: The variance of the residuals is constant

To test the fourth assumption, the researcher needs to look at the final graph of the output. This tests the assumption of homoscedasticity, which is the assumption that the variation in the residuals (or amount of error in the model) is similar at each point of the model. This graph plots the standardised values of this model would predict, against the standardised residuals obtained. As the predicted values increase (along the $\mathrm{X}$-axis), the variation in the residuals should be roughly similar. If everything is ok, this should look like a random array of dots. If the graph looks like a funnel shape, then it is likely that this assumption has been violated. Since it look like a random array of dots, the assumption was met.

Assumption 5: The values of the residuals are normally distributed

This assumption can be tested by looking at the P-P plot for the model. The closer the dots lie to the diagonal line, the closer to normal the residuals are distributed. In this case, from the figure 9, the data points closer and closer to touch the line at all, indicating that assumption 5 was met.

Assumption 6: There are no influential cases biasing the data model

The final assumption can be tested by going back to data file and looking at the Cook's distance values and specified for SPSS to save. It could be seen SPSS has created a new column in the data file. This contains the Cook's Distance statistic for each participant. Any values over 1 were likely to be significant outliers, which may place undue influence on the model, and should therefore be removed and the analysis rerun. In this case, no such instances have occurred.

\section{Summary of assumption test}

Assumption 1: The relationship between the independents variables and the dependent variable is linear

Scatterplots show that this assumption had been met (although it would be needed to formally test each independent variable in this study). 
Assumption 2: There is no multi-Collinearity in the data

Analysis of Collinearity statistics show this assumption has been met, as VIF scores were well below 10, and tolerance scores above 0.2 (statistics $=1.36$ and .74 respectively).

Assumption 3: The values of the residuals are independent

The Durbin-Watson statistic showed that this assumption had been met, as the obtained value was close to 2 (Durbin-Watson $=1.93)$.

Assumption 4: The variance of the residuals is constant

The plot of standardised residuals and standardised predicted values showed no obvious signs of funnelling; suggesting the assumption of homoscedasticity has been met.

Assumption 5: The values of the residuals are normally distributed

The P-P plot for the model suggested that the assumption of normality of the residuals may have been violated. However, as only extreme deviations from normality are likely to have a significant impact on the findings, the results are probably still valid.

Assumption 6: There are no influential cases biasing the model

Cook's Distance values were all under 1, suggesting individual cases were not unduly influencing the model.

Table.1 Proportionate sample size

\begin{tabular}{lcccc}
\hline S/N & $\begin{array}{c}\text { The name of } \\
\text { SACCO's }\end{array}$ & $\begin{array}{c}\text { The number } \\
\text { of members }\end{array}$ & $\begin{array}{l}\text { Proportion to } \\
\text { sample size }\end{array}$ & $\begin{array}{c}\text { Sample taken from } \\
\text { each SACCO's }\end{array}$ \\
1. & Ogey barnot & 642 & $\underline{275^{*} 642=199}$ & 199 \\
885 & 76 \\
2. & Yekatiti 25 & 243 & $\underline{275}^{*} 243=76$ & 785 \\
\hline
\end{tabular}

Source: woreda promotion office, (2018).

Table1 Mean value categorization

\begin{tabular}{cll}
\hline S/N & Mean score categories & Interpretation /Level \\
1. & $<=2.4$ & Low \\
2. & $>=2.5$ and $<=3.4$ & Medium \\
3. & $>=3.5$ & High \\
\hline
\end{tabular}

Source: taken from Ahmed (2013).

Table.3 Reliability Coefficients (Cronbach's Alphas)

\begin{tabular}{ccc}
\hline S/N & Service quality dimensions & Cronbach's Alpha if Item Deleted \\
1. & Tangible & .920 \\
2. & Reliability & .901 \\
3. & Responsiveness & .901 \\
4. & Assurance & .897 \\
5. & Empathy & .899 \\
6. & Overall members satisfaction & .902 \\
\hline
\end{tabular}

Source: own survey (2018). 
Table.4 Mean score and standard deviation for tangibility

\begin{tabular}{lccc}
\hline & N & Mean & $\begin{array}{c}\text { Std. } \\
\text { Deviation }\end{array}$ \\
The SACCO's has modern looking equipment. & & & \\
The SACCO's physical features are visually appealing. & 272 & 3.1140 & 1.18954 \\
The SACCO's reception desk employees are neat appearing. & 272 & 2.7500 & 1.15097 \\
Materials associated with the service (such as pamphlets or & 272 & 2.6838 & 1.24901 \\
statements) are visually appealing at the SACCO's. & & & 1.19780 \\
Tangible & $\mathbf{2 7 2}$ & $\mathbf{2 . 9 4 2 7}$ & $\mathbf{. 8 7 5 1 0}$ \\
Valid N (list wise) & 272 & & \\
\hline
\end{tabular}

Source: own survey (2018).

Table.5 Mean score and standard deviation for reliability

When the SACCO's promises to do something by a certain time, it does so.

$\begin{array}{llr}\text { N } & \text { Mean } & \text { Std. Deviation } \\ 272 & 3.6287 & 1.19886 \\ & & \\ 272 & 3.5441 & 1.09926 \\ 272 & 3.3603 & 1.22202 \\ 272 & 3.2647 & 1.18562 \\ 272 & 3.0588 & 1.11193 \\ \mathbf{2 7 2} & \mathbf{3 . 3 7 1 3} & \mathbf{. 8 4 5 3 4} \\ 272 & & \end{array}$

When you have a problem, the SACCO's shows a sincere interest in solving it.

The SACCO's performs the service right the first time.

The SACCO's provides its service at the time it promises to do so.

The SACCO's insists on error free records.

Reliability

Valid N (list wise)

Source: own survey (2018).

Table.6 Mean score and standard deviation for responsiveness

\begin{tabular}{|c|c|c|c|}
\hline & $\mathrm{N}$ & Mean & $\begin{array}{c}\text { Std. } \\
\text { Deviation }\end{array}$ \\
\hline Employees in the SACCO's tell you exactly when the services will be performed. & 272 & 3.3640 & 1.21638 \\
\hline Employees in the SACCO's give members prompt service. & 272 & 3.1618 & 1.27549 \\
\hline Employees in the SACCO's are always willing to help you. & 272 & 3.4632 & 1.16155 \\
\hline Employees in the SACCO's are never too busy to respond to your request. & 272 & 3.1103 & 1.22503 \\
\hline Responsiveness & 272 & 3.2748 & .99193 \\
\hline Valid N (list wise) & 272 & & \\
\hline
\end{tabular}

Source: own survey (2018).

Table.7 Mean score and standard deviation for assurance

\begin{tabular}{lrrr} 
The behaviour of employees in the SACCO's instils confidence in you. & 272 & 3.4412 & 1.20739 \\
You feel safe in your transactions with the SACCO's. & 272 & 3.6544 & 1.12587 \\
Employees in the SACCO's are consistently courteous with you. & 272 & 3.3309 & 1.15292 \\
Employees in the SACCO's have the knowledge to answer your & 272 & 3.3199 & 1.16716 \\
questions. & $\mathbf{2 7 2}$ & $\mathbf{3 . 4 3 6 6}$ & $\mathbf{. 9 5 3 1 8}$ \\
Assurance & 272 & & \\
Valid N (list wise) & & \\
\hline
\end{tabular}

Source: own survey (2018). 
Table.8 Mean score and standard deviation for empathy

\begin{tabular}{lrrr}
\hline & N & Mean & Std. Deviation \\
The SACCO's gives you individual attention. & 272 & 3.1801 & 1.11708 \\
The SACCO's has operating hours convenient to all its customers. & 272 & 3.3529 & 1.14634 \\
The SACCO's has employees who give members personal attention. & 272 & 3.1507 & 1.18854 \\
The SACCO's has your best interests at heart. & 272 & 3.2941 & 1.16288 \\
The employees of the SACCO's understand your specific needs. & 272 & 3.2353 & 1.20721 \\
Empathy & $\mathbf{2 7 2}$ & $\mathbf{3 . 2 4 2 6}$ & $\mathbf{8 8 3 1 0}$ \\
Valid N (list wise) & 272 & & \\
\hline
\end{tabular}

Source: own survey (2018).

Table.9 Mean score and standard deviation of Service quality dimensions

\begin{tabular}{lccc}
\hline & $\mathrm{N}$ & Mean & Std. Deviation \\
Tangible & 272 & 2.9427 & .87510 \\
Reliability & 272 & 3.3713 & .84534 \\
Responsiveness & 272 & 3.2748 & .99193 \\
Assurance & 272 & 3.4366 & .95318 \\
Empathy & 272 & 3.2426 & .88310 \\
Over all service quality & $\mathbf{2 7 2}$ & $\mathbf{3 . 2 5 8 4}$ & $\mathbf{. 7 6 9 9 0}$ \\
Valid N (list wise) & 272 & & \\
\hline
\end{tabular}

Source: own survey (2018).

Table.10 Mean score and standard deviation for satisfactions members' satisfaction

\begin{tabular}{lccr} 
& N & Mean & Std. Deviation \\
The SACCO completely meets my expectations. & 272 & 3.3529 & 1.15276 \\
I feel absolutely delighted with the SACCO's services. & 272 & 3.3934 & 1.16040 \\
The information that is presented by this SACCOS is accurate. & 272 & 3.4007 & 1.10904 \\
This SACCO is exactly what I need. & 272 & 3.4044 & 1.17714 \\
There are guarantees of this SACCO's. & 272 & 3.8051 & 1.12777 \\
Overall, the SACCO is able to satisfy my wants and needs. & 272 & 3.6250 & 1.14252 \\
Over all members satisfaction & $\mathbf{2 7 2}$ & $\mathbf{3 . 4 9 6 9}$ & $\mathbf{8 7 6 0 2}$ \\
Valid N (list wise) & 272 & & \\
\hline
\end{tabular}

Source: own survey (2018).

Table.11 Correlation of service quality dimensions and overall service satisfaction

\begin{tabular}{llc}
\hline \multirow{2}{*}{ Tangible } & Pearson Correlation & over all members satisfaction \\
& Sig. (2-tailed) & $.548^{* *}$ \\
Reliability & $\mathrm{N}$ & .000 \\
& Pearson Correlation & 272 \\
& Sig. (2-tailed) & $.700^{* *}$ \\
Responsiveness & $\mathrm{N}$ & .000 \\
& Pearson Correlation & 272 \\
Assurance & Sig. (2-tailed) & $.629^{* *}$ \\
& $\mathrm{~N}$ & .000 \\
& Pearson Correlation & 272 \\
Empathy & Sig. (2-tailed) & $.690^{* *}$ \\
& $\mathrm{~N}$ & .000 \\
& Pearson Correlation & 272 \\
& Sig. (2-tailed) & $.744^{* *}$ \\
& $\mathrm{~N}$ & .000 \\
\hline
\end{tabular}

Source: own survey (2018). 
Table.12 Model Summary

\begin{tabular}{lccccc}
\hline Model & $\mathrm{R}$ & $\mathrm{R}$ Square & Adjusted R Square & Std. Error of the Estimate & Durbin-Watson \\
1 & $.803^{\mathrm{a}}$ & .645 & .639 & .52665 & 1.825 \\
a. Predictors: (Constant), Empathy, Tangible, Reliability, Responsiveness, Assurance & \\
b. Dependent Variable: over all members satisfaction & \\
\hline
\end{tabular}

Source: own survey (2018).

Table.13 ANOVA

\begin{tabular}{llccccc}
\hline \multirow{2}{*}{ Model } & \multicolumn{5}{c}{ ANOVA $^{\mathbf{a}}$} \\
& Sum of Squares & $\mathrm{df}$ & Mean Square & $\mathrm{F}$ & Sig. \\
1 & Regression & 134.193 & 5 & 26.839 & 96.766 & $.000^{\mathrm{b}}$ \\
\multicolumn{2}{l}{ Residual } & 73.777 & 266 & .277 & & \\
T. Dependent Variable: over all members satisfaction & 271 & & & \\
b. Predictors: (Constant), Empathy, Tangible, Reliability, Responsiveness, Assurance \\
\hline
\end{tabular}
Source: own survey (2018)

Table.14 Summary output of multiple linear regression analysis

\begin{tabular}{|c|c|c|c|c|c|c|c|c|}
\hline \multicolumn{2}{|c|}{ Model } & \multicolumn{2}{|c|}{$\begin{array}{l}\text { Unstandardized } \\
\text { Coefficients }\end{array}$} & \multirow{3}{*}{$\begin{array}{c}\text { Standardized } \\
\text { Coefficients } \\
\text { Beta }\end{array}$} & \multirow[t]{2}{*}{$\mathrm{t}$} & \multirow[t]{2}{*}{ Sig. } & \multicolumn{2}{|c|}{$\begin{array}{c}\text { Collinearity } \\
\text { Statistics }\end{array}$} \\
\hline & & B & $\begin{array}{l}\text { Std. } \\
\text { Error }\end{array}$ & & & & $\begin{array}{c}\text { Toleran } \\
\text { ce }\end{array}$ & VIF \\
\hline \multirow[t]{6}{*}{1} & (Constant) & .506 & .143 & & 3.547 & .000 & & \\
\hline & Tangible & .066 & .048 & .066 & 1.382 & .168 & .584 & 1.712 \\
\hline & Reliability & .297 & .060 & .287 & 4.985 & .000 & .403 & 2.481 \\
\hline & $\begin{array}{l}\text { Responsivenes } \\
\mathrm{s}\end{array}$ & -.016 & .055 & -.019 & -.300 & .765 & .345 & 2.900 \\
\hline & Assurance & .171 & .059 & .186 & 2.903 & .004 & .326 & 3.065 \\
\hline & Empathy & .389 & .058 & .393 & 6.710 & .000 & .390 & 2.566 \\
\hline
\end{tabular}

Source: own survey (2018)

Table.15 The hypothesis test result

\begin{tabular}{lll}
\hline $\begin{array}{l}\text { Null } \\
\text { hypothesis } \\
\mathbf{H}_{\mathbf{1}}\end{array}$ & Description & result \\
$\mathbf{H}_{\mathbf{2}}$ & $\begin{array}{l}\text { There is positive and significant relationship between assurance and } \\
\text { customer satisfaction } \\
\text { There is positive and significant relationship between empathy and customer } \\
\text { satisfaction }\end{array}$ & Accepted \\
$\mathbf{H}_{\mathbf{3}}$ & $\begin{array}{l}\text { There is positive and significant relationship between reliability and } \\
\text { customer satisfaction } \\
\text { There is positive and significant relationship between responsiveness and } \\
\text { customer satisfaction }\end{array}$ & Accepted \\
$\mathbf{H}_{\mathbf{4}}$ & $\begin{array}{l}\text { There is positive and significant relationship between tangible and customer } \\
\text { satisfaction }\end{array}$ & Accepted \\
$\mathbf{H}_{\mathbf{5}}$ & $\begin{array}{l}\text { The service quality dimensions assurance, empathy, reliability, } \\
\text { responsiveness, and tangible explain the customer satisfaction significantly } \\
\text { The service quality dimensions tangible and responsiveness }\end{array}$ & Accepted \\
$\mathbf{H}_{\mathbf{6}}$ & Rejected \\
& & \\
\hline
\end{tabular}


Figure.1 Percentage of sample respondents' satisfied with tangible

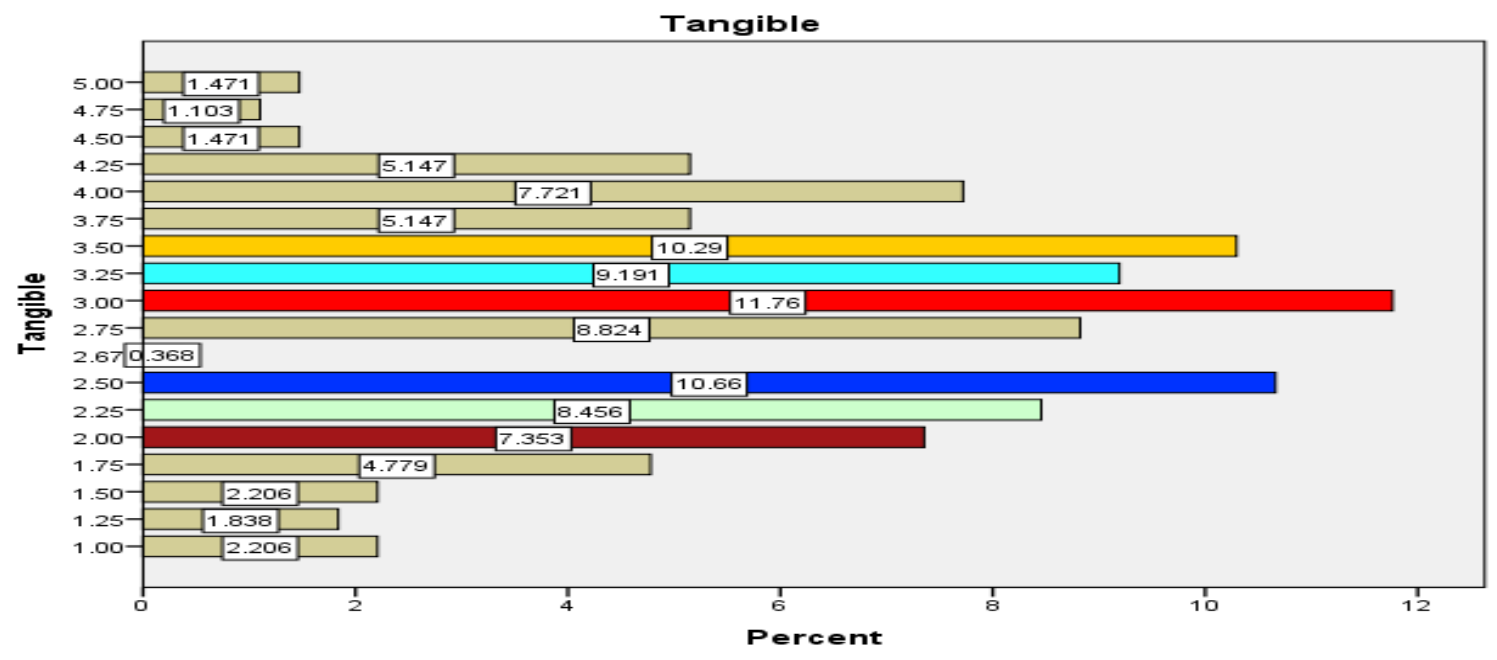

Source: own survey (2018).

Figure.2 Percentage of sample respondents' satisfaction with reliability

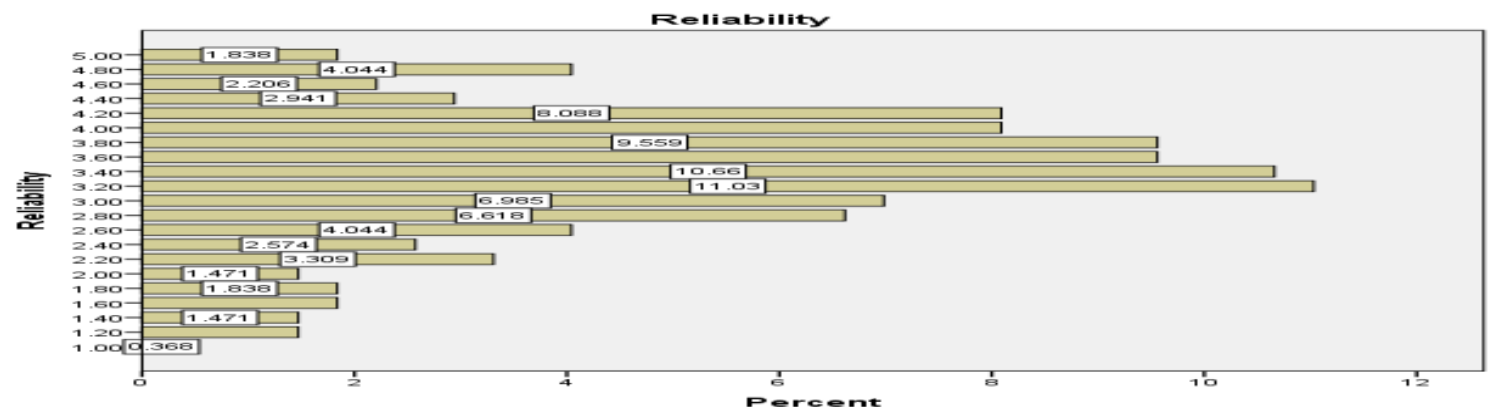

Source: own survey (2018).

Figure.3 Percentage of sample respondents' satisfaction with responsiveness

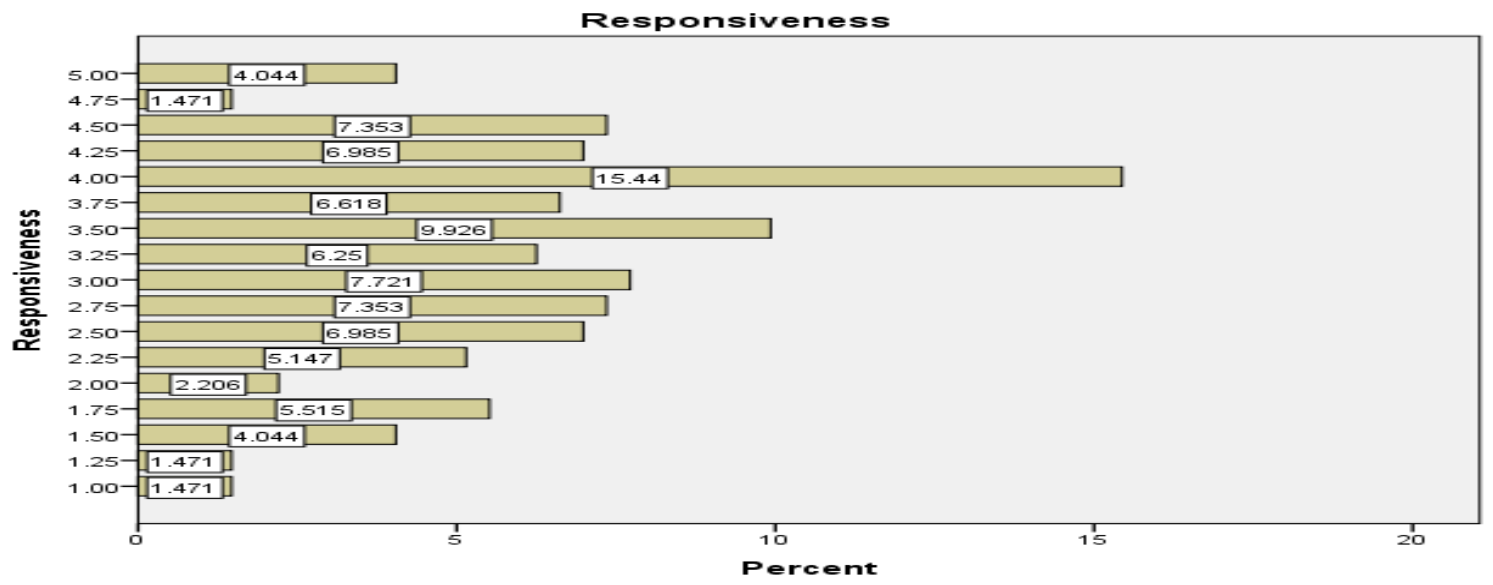

Source: own survey (2018) 
Figure.4: Percentage of sample respondents' satisfaction with assurance

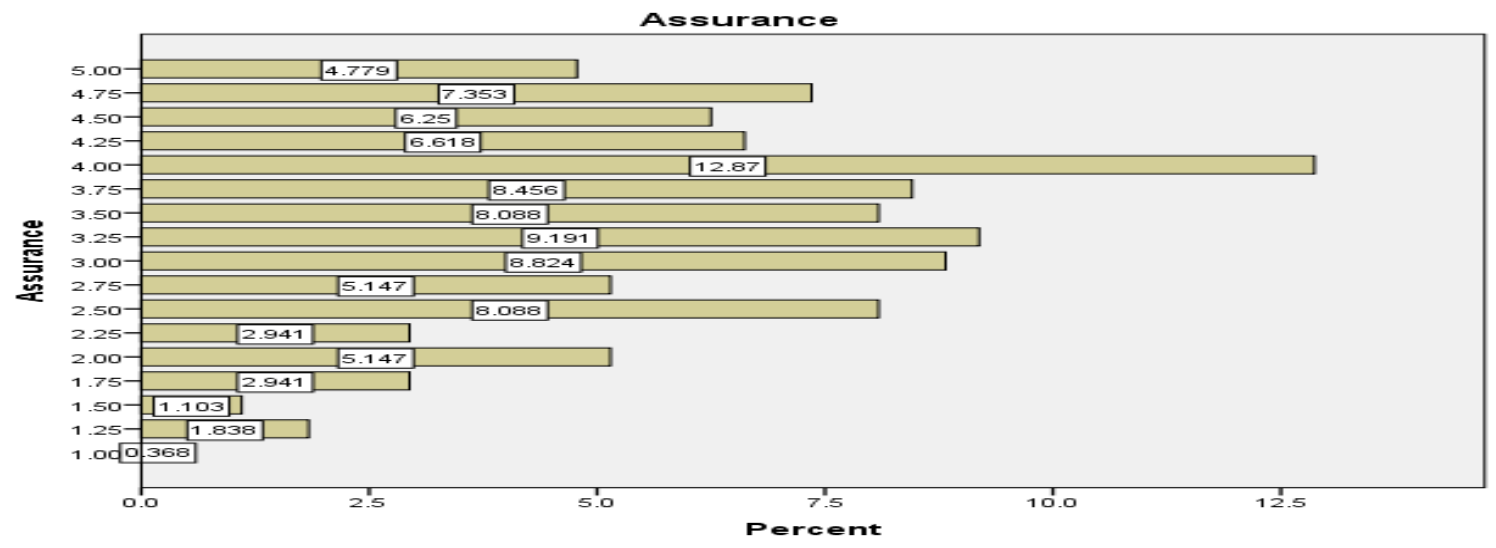

Source: own survey (2018).

Figure.5 Percentage of sample respondents' satisfaction with empathy

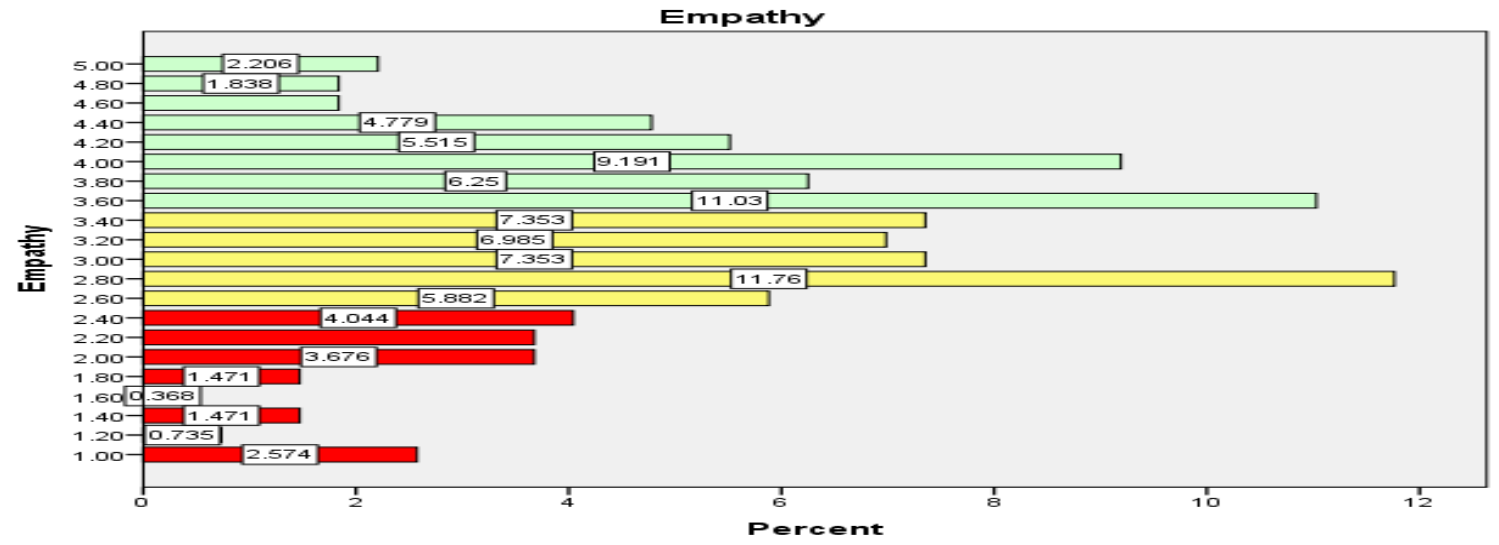

Source: own survey (2018).

Figure.6 Overall level of service quality

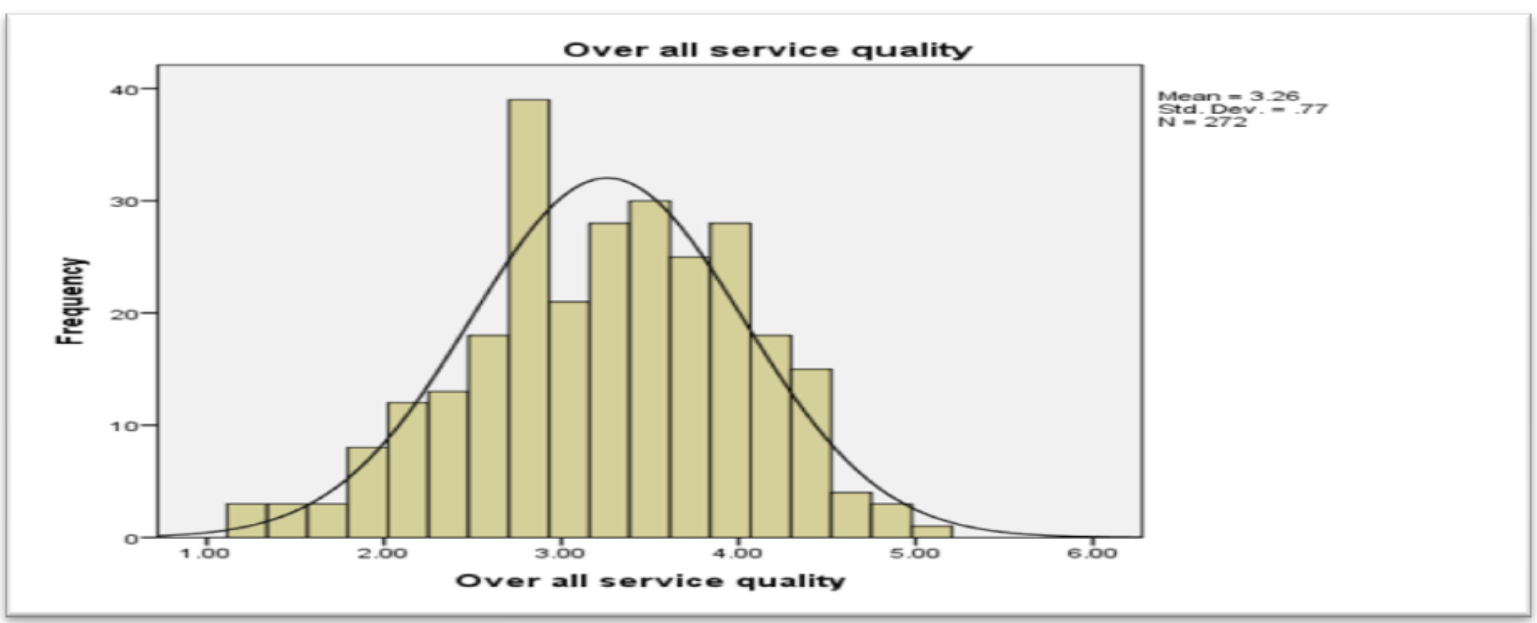

Source: own survey (2018) 
Figure.7 The percentage of sample respondents satisfied with SACCO's services

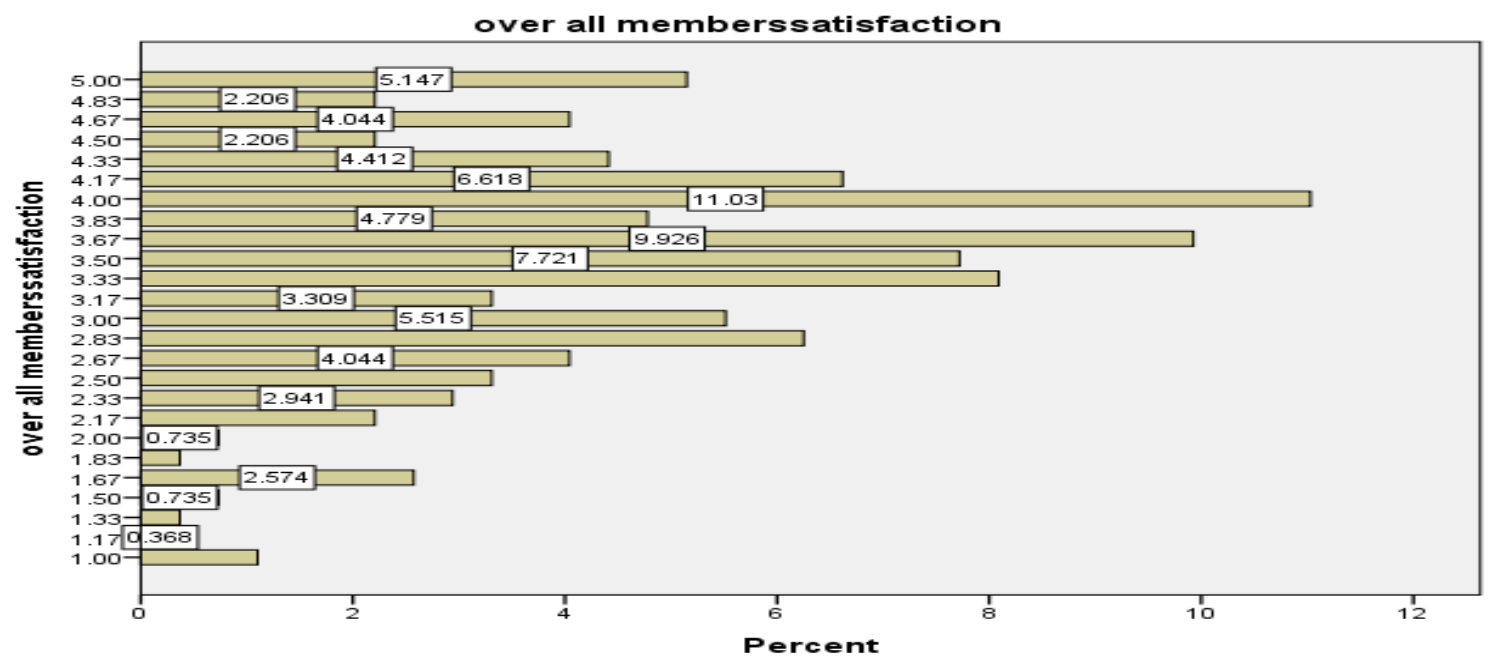

Source: own survey (2018).

Figure.8 Overall level of members' satisfaction

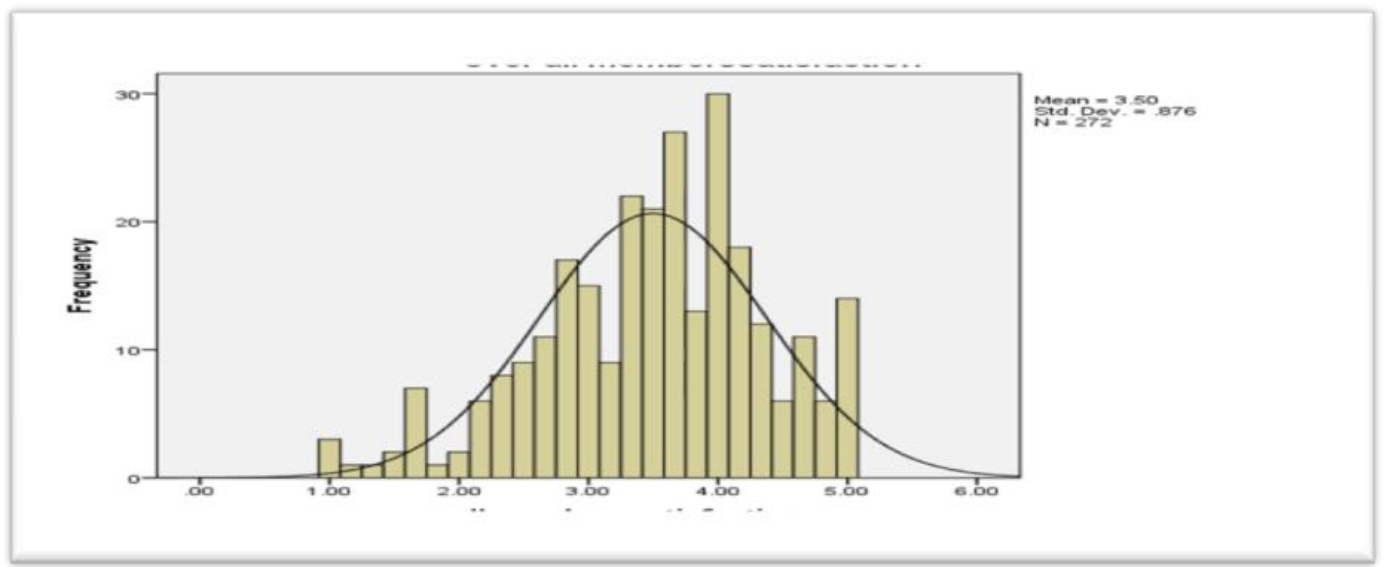

Source: own survey (2018.)

Figure.9 Homoscedasticity

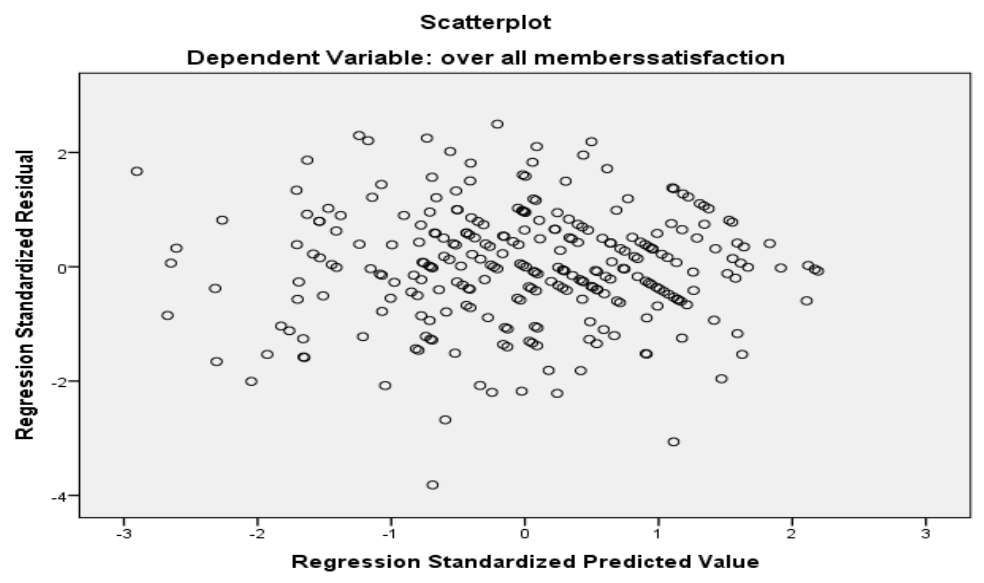

Source: own survey (2018). 
Fig.10 Normal distribution of residuals

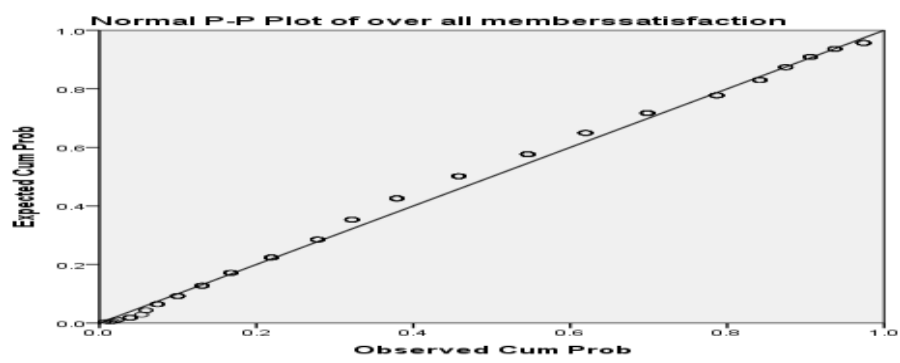

Source: own survey (2018).

The above table 12 showed that the multiple linear regression model summary and overall fit statistics. From the table 12 below it was observed that the adjusted $\mathrm{R}^{2}$ of our model 0.639 with the $\mathrm{R}^{2}=0.645$. This means that the linear regression model with the independent variables tangibility, reliability responsiveness, assurance and empathy explains $64.5 \%$ of the variance of the members' satisfaction. The DurbinWatson $\mathrm{d}=1.825$, which is between the two critical values of 1.5 and $2.5(1.5<\mathrm{d}<2.5)$, and therefore it can be assumed that there is no first order linear autocorrelation in our multiple linear regression data.

The table 13 is the F-test, or ANOVA. The F-Test is the test of significance of the multiple linear regression. The F-test has the null hypothesis that there is no linear relationship between the variables (in other words $R^{2}=0$ ). The F-test of or Model 1 is highly significant, thus it can be can assume that there is a linear relationship between the variables in our model.

From the table 14 above, there were multiple independent variables in the analysis; the Beta weights compare the relative importance of each independent variable in standardized terms. From this model output, it was possible to put the importance of each independent variables in order based on the values of Beta coefficient each variables. Therefore, empathy the first $($ Beta $=\mathbf{0 . 3 9 3})$, reliability the second $(\mathbf{0 . 2 8 7})$, assurance the third (0.186), tangible the fourth $(\mathbf{0 . 0 6 6 )}$ and responsiveness the fifth $(\mathbf{- 0 . 0 1 9 )}$.

This table also checks for multi-Collinearity in multiple linear regression model. Multi-Collinearity is the extent to which independent variables are correlated with each other. Tolerance should be greater than 0.1 (or VIF < 10) for all variables. If tolerance is less than 0.1 there is a suspicion of multi-Collinearity, and with tolerance less than 0.01 there is proof of multi-Collinearity.
Homoscedasticity and normality of residuals was checked with an eyeball test of the P-P Plot of $Z^{*}$ Pred and $\mathrm{Z}^{*}$ Presid. The plot indicated that in this multiple linear regression analysis there is no tendency in the error terms.

The researcher investigated the relationship between the customer satisfaction and the five dimensions of service quality (tangibility, assurance, reliability, assurance and empathy). Hence, the enter method multiple linear regression analysis found that service quality dimensions (reliability, assurance and empathy) have significant and relevant explanatory power over members' satisfaction , but tangible and responsiveness were found to be insignificant and didn't have explanatory power.The findings of this research similar with (Bersisa, 2015) except, tangibility found to be significant in the case of (Bersisa, 2015).

Together the estimated regression model (overall members, satisfaction $=0.506+0.066$ Tangible +0.297 Reliability -0.016Responsiveness +0.171Assurance +0.389Empathy) explains $64.5 \%$ of the variance of the members' satisfaction with an adjusted $\mathrm{R}^{2}$ of $63.9 \%$. The regression model is highly significant with $(\mathrm{p}<\mathbf{0 . 0 0 1})$ and $(\mathrm{F}=\mathbf{9 6 . 7 6 6})$. The standard error of the estimate was $(\mathbf{0 . 5 2 6 6 5})$.According to the analysis of the dependent variable and independent variables; the three independent variables tangibility, reliability, assurance and empathy were influencing members' satisfaction significantly at $95 \%(\alpha=\mathbf{0 . 0 5})$ confidence level. However, responsiveness and tangible didn't have a significant influence on customers' satisfaction at $95 \%(\alpha=\mathbf{0 . 0 5})$ confidence level. The focus group discussion held with selected respondents support this finding. According to the FGD, they would give high emphases to assurance, reliability and empathy to evaluate whether SACCO, s satisfying them or not. 
Thus, the researcher can not only show a linear relationship between service quality dimensions which was strong and positive., but, can also conclude that for everyone unit of increases in tangibility, would increases satisfaction by (0.066); for every one unit increases in reliability would make satisfaction to be increased by(0.297); for every one unit increases in responsiveness would make satisfaction to be decreased $(-0.016)$; for every one unit increases in assurance would make satisfaction to be increased by (0.171) and for every one unit increases in empathy would make satisfaction to be increased by (0.389).

Therefore, as per of this model analysis output, only three service quality dimensions (empathy, assurance and reliability) were explained satisfaction significantly whereas the other two service quality dimensions (tangibility and responsiveness) were found to be in significant. Therefore, the results of hypothesis with decision whether to support or reject has shown on table 15.

Based on the analysis of the data and findings of this study, the following conclusions were drawn:

i. From the demographic characteristics of sample respondents, one can concluded that the SACCO's has more male members than female and has members who have relatively long relationship with the SACCO's as most of the members stayed in membership in urban SACCO's for about 1-4 four years. In addition, it was possible to conclude that the urban SACCO's members were educated since majority of sample respondents were first degree holder. Finally what could be concluded from this research finding was, many numbers of SACCO's members monthly income level was belonged to 4001-7000 birr income category.

ii. As far as urban SACCO's service quality and members' satisfaction level to service quality experienced conclusion was concerned, urban SACCO's service quality level was low and members' service satisfaction was high. This means that, even though the service quality level of urban SACCO's was low, members' satisfaction level was high.

iii. As far as mean score of the service quality dimensions conclusion were concerned, from the descriptive analysis one concluded that assurance has highest mean whereas tangible mean was lowest. iv. From these research findings, it could be concluded that members were satisfied $73.16 \%, 85.66 \%$, $80.15 \%, 85.6 \%$ and $80.99 \%$ to the tangibility, reliability, responsiveness, assurance and empathy respectively.

v. From this study it is possible to conclude that $88.6 \%$ sample respondents were satisfied with the overall services of urban saving and credit cooperatives.

vi. The correlation analysis showed that there exist significant and positive relationships between the five service quality dimensions and customers satisfaction. Therefore, improvement in all service quality dimensions not only brings the level of the service quality to the customers' expectation but also increases customers' satisfactions which result in customer retention, repeated visit, positive word of mouth, increased profitability.

vii. From the multiple linear regression analysis finding, it was possible to conclude that empathy, assurance and reliability explained members' satisfaction significantly whereas tangible and responsiveness found to have in significant effect on members satisfaction.

\section{Recommendation}

Microfinance customers now days becoming more sophisticated concerning the quality of service they required or expects. The microfinance sector is losing customers because of both the aggressive competition and MFIs' weakness to satisfy their clients. Therefore, to survive in a competitive environment, urban saving and credit cooperative societies should have to improve the quality service dimension significantly explaining members' satisfaction in order to increase members' satisfaction level. As per of this research finding and conclusion drawn from it, the following recommendation spelt out.

From the finding of this study, the assurance explained members' satisfaction significantly. Therefore, in order to improve members satisfaction, SACCCO's has to shape the behaviours of the employees in away members fill confidence at employees, providing education and training for employees in order to upgrade employees knowledge and skill enables them to process members transactions safely, serving members in a dependably manner through courteous at them and answers the members' questions.

From the findings of this research, the reliability was found to be significant. Therefore, it has explanatory 
power over members' satisfaction. So, improvement of it would lead to the improvement of members' satisfaction. In order to improve reliability dimension of service quality, the following recommendation has to be taken into account. When SACCO's promised to do something by certain time, it has to keep promise and perform accordingly. The other one was when members faced a certain problem; the SACCO's has to show sincere interest in solving members' problem. Finally, the SACCO' should have to have error free records.

The result of this investigation revealed that empathy dimension of service quality dimensions explaining the members' satisfaction significantly. Therefore, enhancement in empathy dimension would increase the members' satisfaction. In order to increase the empathy, SACCO's should have to gives members individual attention, has operating hours convenient to all members, give members personal attention, serve members with best interest from heart and understand members' specific need.

\section{References}

Abdullah, F., Suhaimi, R., Hamali, J., and Saban, G. (2011). Bank Service Quality (BSQ) Index: An Indicator of Service Performance. International Journal of Quality and Reliability Management, 28(5), 542-555.

Angur, M. G., Natarajan, R., and Jahera, J. J. (1999). Service quality in the banking industry: an assessment in a developing economy. The International Journal of Bank Marketing., 17(3), 116-25.

Arasli, H., Katircioglu, S. T., and Mehtap-Smadi, S. (2005). A comparison of service quality in the banking industry: Some evidence from Turkish and Greek -speaking areas in Cyprus. International Journal of Bank Marketing., 23(7), 508-526.

Aredo, D. (1993). The informal and semi-formal financial sectors in Ethiopia: A study of the iqqubb, eddir and saving and credit cooperatives, AAU, Ethiopia.

Asfaw, F. (2015). The Impact of Service Quality on Customer Satisfaction and Loyalty in the Ethiopian Insurance Industry: master thesis, AAU.

Avkiran, N. K. (1994). Developing an instrument to measure customer service quality in branch banking. International Journal of Bank Marketing., 12(6), 1018.
B. A. (2003). Banking on social change: Grameen Bank lending to women. International journal of Politics culture, and Society, 16(3) 369-385.

Bagozzi, R. P. (1992). The self regulation of attitudes, intentions, and behaviour. Social Psychology quarterly, 55, 178-204.

Barnes, B. (2005). Analyzing Service Quality: The Case of Post-Graduate Chinese Students", Leeds University Business School , 2.

Beerlin, A., Martin, J. D., and Quitana, A. (2004). A model of customer loyalty in the retail banking market. European Journal of Marketing., 38(1/2), 253-275.

Bernasek, A. (2003). Banking on social change : Gameen Bank lending to Women . International Journal of Politics, Culture , and Society., 16(3), 369-385.

Bersisa, G. (2015). Assessment of Service Quality and Its Influence on Customer Satisfaction: The Case of Oromia International Bank SC. Master thesis, AAU.

Bhattacharyya, S. K., and Rahman, Z. (2004). Capturing the customer voice, the centerpiece of strategy making a case study in banking. European business review., 16(2), 128-138.

Bhattacherjee , A. (2001). Understanding information systems continuance: an expectation- confirmation model. MIS quarterly, Pp. 351-370.

Bitner, M. J., Booms, B. H., and Tetreault, M. S. (1990). The service encounter: diagnosing favourable and unfavorable incidents. Journal of Marketing., 54(1), 71-84.

Bloemer, J., and Kode Ruyter,et al., (1999). Linking perceived service quality and service loyalty: a multi-dimensional perspective. European Journal of Marketing, 33, 1082.

Bojanic, D. C. (1991). "Quality Measurement in Professional Services Firms,". Journal of Professional Service Marketing., 7(2),27-36.

Bolton, R. N., and James, H. D. (1991). Bolton, Ruth N., and James H. Drew (1991), "A Longitudinal Analysis of the Impact of service changes on customer attitude. Journal of marketing., 55(1), 1-9.

Brown, S. W., and Teresa, A. S. (1989). "A Gap Analysis of Professional service quality. Journal of Marketing, 53(April), 92-98.

Carman, J. M. (1990). "Consumer Perceptions of Service Quality: An Assessment of the SERVQUAL Dimensions",. Journal of Retailing., 66 (I), 33-55.

Chowdhary, N., and Prakash, M. (2007). Prioritizing service quality dimension. Managing service quality., 17(5), 493-509.

Cristobal, E., Flaviain, C., and Guinaliu, M. (2007). Perceived e-service quality: measurement validity 
and effects on consumer satisfaction and web site loyalty. Managing Service Quality., 17(3), 317-340.

Cronin, J. J., Brady, M. K., and Hult, G. T. (2000). Assessing the effects of quality, value and customer satisfaction on consumer behaviour intention in service invirments. Journal of Retailing, 76(2), 193218.

Cronin, Jr, J. J., and Steven, A. T. (1992). Cronin, Jr. J. Joseph, and Steven A. Taylor (1992), "Measuring Service Quality: A reexamination and extension. Journal of Marketing., 56(July), 55-68.

Cropp, k. A. (1980). cooperative principles and practices in 21st century . Madison: university of Wiscosin Extension .

Culiberg, B. (2010). Identifying service quality dimensions as antecedents to customer satisfaction

\section{How to cite this article:}

Belay Yadeta and Wondmagegn Urgessa. 2019. Members' Satisfaction with the Service Performance of Urban Saving and Credit Cooperative Societies: The case of Gadeb-Hasasa Woreda: Ethiopia. Int.J.Curr.Res.Aca.Rev. 7(3), 56-74. doi: https://doi.org/10.20546/ijcrar.2019.703.005 in retail banking. Economic and Business Review. Economic and Business Review., 12(3), 151-166.

Daubert. (2002). le Marketing au service des IMF, 6, BIM.

Davies, Duane, and Gordon, P. (1987). Identifying components of service quality: The case of health and fitness industry Un published Working Paper . Department of Marketing, University of Central Florida.

Dharmalingam, S., and Kannan, K. V. (2011). Customer perception on service quality of new private sector banks in Tamilnadu - an empirical study. Journal of Banking Financial Services and Insurance Research, 1(5), 39-49. 